\title{
A influência da estrutura de um grupo na linguagem escrita de idosos: um estudo de caso
}

\author{
The influence of group structure in the written language of \\ elderly subjects: a case report
}

\author{
Paulo Penha de Souza Filho ${ }^{1}$, Giselle Aparecida de Athayde Massi ${ }^{1}$
}

\begin{abstract}
RESUMO
Este estudo tem como objetivo analisar o papel de um grupo de idosos no desenvolvimento de atividades voltadas à escrita de uma das participantes desse grupo, que se consolidou em função de uma Oficina de Linguagem. Trata-se de um relato de caso que partiu de um paradigma interpretativo, o qual inclui subjetividade, interesses, emoções e valores pessoais. Foram realizadas análises da transcrição da entrevista semi-estruturada realizada com uma integrante de 85 anos de uma Oficina de Linguagem, situada em Curitiba. Para a entrevistada, a Oficina é um ambiente que a engrandece, pois se sente incentivada, acolhida pelo grupo e consegue expor fatos de sua vida por meio da escrita. Foi sua participação no grupo que, segundo seus próprios relatos, despertou-lhe desejo e coragem para relembrar, reorganizar e traduzir suas histórias em palavras para serem lidas por outros. Pode-se perceber a estreita relação entre o vínculo que a entrevistada estabelece com o grupo e as suas possibilidades de produções escritas. Participar do mesmo vem gerando mudanças e transformações na forma de a entrevistada se relacionar com suas produções escritas que são elaboradas durante a organização de relatos de suas histórias de vida no e para o grupo.
\end{abstract}

Descritores: Envelhecimento; Escrita manual; Estrutura de grupo; Relações interpessoais; Estudos de linguagem

\section{INTRODUÇÃO}

Aproximadamente $60 \%$ das pessoas idosas vivem nos países em desenvolvimento ${ }^{(1)}$. O Brasil está nessa estatística, em que o número de pessoas idosas já alcança $10 \%$ de sua população total e vem aumentando aceleradamente ${ }^{(2)}$.

Com o crescimento da longevidade humana e consequentemente da população idosa, é preciso considerar uma vida com qualidade e autonomia ${ }^{(3)}$. Discussões sobre aspectos que permeiam a população idosa se intensificaram, em nosso país, a partir de meados dos anos 70. De um ponto de vista amplo, tendo em vista que estudos e reflexões sobre essa população são relativamente recentes, é possível afirmar que nossos conhecimentos sobre processo de envelhecimento e os idosos brasileiros são incipientes ${ }^{(4)}$. De qualquer forma, entendemos que para alcançarmos qualidade de vida satisfatória no processo de envelhecimento é necessário que encontremos suporte para lidarmos com questões singulares de cada sujeito que envelhece.

Trabalho realizado no Programa de Pós-Graduação em Distúrbios da Comunicação, Universidade Tuiuti do Paraná - UTP - Curitiba (PR), Brasil.

(1) Programa de Pós-graduação (Mestrado e Doutorado) em Distúrbios da Comunicação da Universidade Tuiuti do Paraná - UTP - Curitiba (PR), Brasil. Endereço para correspondência: Paulo Penha de Souza Filho. Av. República Argentina, 665/701, Água Verde, Curitiba (PR), Brasil, CEP: 80240-210. E-mail: ppsf@terra.com.br

Recebido em: 20/12/2010; Aceito em: 14/3/2011
Uma via facilitadora de acesso a essa subjetividade é o trabalho com a linguagem, pois ela não é um simples veículo de informação, mas o resgate do homem como um ser social, histórico e cultural. A linguagem promove a (re)organização contínua da história de cada sujeito, tornando-os autores da vida singular, que está em constituição permanente, e a interação social depende de processos interlocutivos que se efetivam no espaço de produção da linguagem ${ }^{(5)}$.

Nessa perspectiva, proposta pela corrente sócio-histórica, o sujeito é o autor das transformações sociais ${ }^{(6)}$. Assim, entendemos que partir do uso efetivo da linguagem, idosos pode significar e avaliar suas vida, suas relações com a família, com o trabalho, com as atividades sociais, com a própria linguagem e suas possibilidades ou dificuldades para o estabelecimento de relações dialógicas e de interação com o outro ${ }^{(2)}$.

Para que o processo interloucutivo possa decorrer do uso significativo da linguagem, o trabalho em grupo pode ser uma opção relevante. Estudos ${ }^{(7)}$ afirmam que a configuração do grupo pressupõe que os sujeitos tomem uma posição de interlocutores uns dos outros e, assim, assumam a condição de sujeitos na dinâmica do grupo. Cabe ressaltar que para que um grupo realmente se constitua, para que as relações se iniciem entre seus membros, devem existir interesses em comum entre os sujeitos participantes, as quais lhe conferem um funcionamento específico.

O foco de intervenção em grupo está no ser humano com 
sua totalidade complexa e multifacetada ${ }^{(8)}$. Ou seja, entendemos que um sujeito é como ele é pela influência que diversos grupos sociais exercem em suas atividades especificas, assim como pela própria atuação desse sujeito único nos grupos que integra. Ao longo da vida, as disposições interpessoais, o desempenho de papéis designados pela cultura e a solução de problemas ocorrem em função de nossas experiências grupais ${ }^{(9)}$.

Um sujeito pode se ver diante de um dilema ou conflito e sentir-se incapacitado para alcançar a resolução de uma situação problemática ${ }^{(5)}$. Mas, o grupo, a partir das relações interpessoais que viabiliza, pode desestabilizar dilemas e diluir conflitos, na medida em que questiona estereótipos sociais e ressalta as individualidades que o compõem. Dessa forma, a cooperação social oferecida pelo grupo pode ser essencial para o bem-estar pessoal, exercendo um importante papel na maneira de seus participantes relacionarem-se com suas próprias singularidades, com suas subjetividades e, por essa mesma via, com a linguagem.

Vale lembrar que para fazer parte de um grupo é necessário que seus membros tenham objetivos em comum, e que a relação com a linguagem começa a se efetivar quando cada participante pode reconhecer seu lugar particular e coletivo e perceber que faz parte daquele grupo. $\mathrm{O}$ grupo pode favorecer $\mathrm{O}$ desenvolvimento de atividades de seus integrantes e a interação entre os mesmos possibilita que eles paulatinamente passem a assumir uma ou mais funções no decorrer do trabalho que estão processando ${ }^{(5)}$. As relações estabelecidas entre diferentes interlocutores, em constituições que podemos denominar como grupos, organizam formas de operar, agir e pensar sobre a linguagem nos seus diferentes modos de manifestação ${ }^{(8)}$.

Atualmente, estudos vêm sendo realizados na tentativa de melhor caracterização e compreensão da população idosa brasileira, bem como de um entendimento capaz de viabilizar a inclusão dessa população na sociedade grafocêntrica atual ${ }^{(10)}$. Nesse sentido, apontamos para a iniciativa da Oficina de Linguagem, a qual tem, desde a sua criação em 2006, desenvolvido atividades focadas na escrita e voltadas à população idosa. Tal Oficina oferece anualmente a todos os idosos, usuários da Unidade de Saúde da Praça Ouvidor Pardinho, em Curitiba, a oportunidade de se inscreverem e participar das atividades durante o ano letivo. As atividades são realizadas, semanalmente, todas as terças-feiras, das 14:30 horas às 16:00 horas.

Além dos integrantes idosos (atualmente dois homens e 11 mulheres), participam do grupo, uma fonoaudióloga que coordena a Oficina, alunos das Graduações em Fonoaudiologia e em Psicologia, bem como discentes do Mestrado e Doutorado em Distúrbios da Comunicação da instituição de origem. Na Oficina são realizadas diversas atividades com e sobre as modalidades oral e escrita da linguagem, tais como: rodas de conversas, relatos de histórias pessoais, leituras de textos levados pela coordenadora do grupo e, também, por seus integrantes, produções de textos escritos, leituras dessas produções, organização de um livro ao final de cada ano, composto dos relatos singulares de cada participante do grupo.

As atividades mencionadas acima, realizadas no decorrer do ano, são direcionadas de forma direta ou indireta para a produção do livro, cujo tema é escolhido no início de cada período pelos integrantes do grupo. Dessa forma, organiza-se, anualmente, por meio dos relatos pessoais elaborados pelos próprios sujeitos participantes da Oficina um livro-texto, no qual ficam registradas partes de suas histórias e de seus projetos de vida.

O objetivo principal dessa Oficina é trabalhar, com grupos de idosos, atividades orais, de leitura e de escrita, que possam garantir aos seus participantes melhores possibilidades de inserção social na comunidade em que vivem ${ }^{(10)}$. Nessa direção, a referida Oficina, em conformidade com pesquisas afeitas ao tema do envelhecimento, busca devolver ao idoso sua função de lembrar, propagar suas historias e experiências, vinculando diferentes gerações ${ }^{(11)}$.

Convém ressaltar que a Oficina de Linguagem desenvolve suas atividades pautada no entendimento de que a linguagem é um processo fundador capaz de significar e ressignificar, em todos os momentos da vida de cada sujeito, o sentido singular de ser, fazer e de estar no mundo. A linguagem, enquanto trabalho social e histórico, viabiliza relações intersubjetivas por meio de processos de escuta e de produção de relatos de vida. A escuta e a produção de tais relatos podem se tornar uma válvula propulsora para uma nova possibilidade de relação tanto com a linguagem oral, com a escrita e, por aí, com a própria vida e com o outro ${ }^{(12)}$.

Foi com este interesse que desenvolvemos a presente pesquisa, cujo objetivo é analisar o papel do grupo de idosos no desenvolvimento de atividades voltadas à linguagem escrita de uma das participantes desse grupo, que se consolidou em função da Oficina de Linguagem, já mencionada anteriormente.

\section{APRESENTAÇÃO DO CASO CLÍNICO}

A pesquisa foi realizada com uma idosa do gênero feminino, com 85 anos de idade, integrante, frequentadora da Oficina de Linguagem, situada na região central de Curitiba, há mais de cinco anos consecutivos. Vale esclarecer que essa Unidade de Saúde volta, preferencialmente, sua atenção para um público idoso.

Consideramos como critérios de inclusão neste estudo ser integrante da Oficina de Linguagem há mais de um ano e ter idade superior a 65 anos. Nesse sentido, o convite foi feito prioritariamente a nossa entrevistada, pois além de ela se encaixar nos requisitos mínimos para a participação neste estudo, ela é a integrante mais antiga da Oficina de Linguagem e, também, a mais idosa. Ela aceitou prontamente o convite que lhe fora feito.

Foi realizada uma entrevista semi-estruturada com a integrante do grupo a partir de 17 questões. Desse total, seis são fechadas, por se tratarem de perguntas voltadas a caracterização do sujeito da pesquisa, e 11 são semi-abertas, que tiveram por objetivo instigar a entrevistada a narrar sobre as significações atribuídas por ela à linguagem escrita, bem como as influências ou não do grupo sobre a relação estabelecida entre ela e essa modalidade de linguagem.

Esse tipo de entrevista parte de um roteiro que inclui os temas a serem discutidos na pesquisa, mas deixa a participante livre para responder a eles sem obedecer à ordem das perguntas e sem precisar limitar-se estritamente ao que foi perguntado ${ }^{(13)}$. As questões semi-abertas abordaram os seguintes pontos: 
tempo e justificativas para a participação no grupo da Oficina de Linguagem; motivos que a levaram a relatar parte da sua história de vida para esse grupo; percepção sobre as mudanças geradas na sua relação com a escrita devido às influências do grupo; e, por fim, como ela se percebe dentro do grupo.

Optamos pela entrevista oral, com a gravação das perguntas e respostas na íntegra com gravador digital de áudio, pois partimos do pressuposto que, dessa forma, a idosa (sujeito dessa pesquisa) se sentiria mais livre para expor suas emoções e valores. Após a realização da entrevista, as respostas foram transcritas em arquivo Word para posterior análise.

Para atingir o objetivo do presente estudo, partimos de um paradigma interpretativo. $\mathrm{O}$ interesse central desse paradigma é o significado humano da vida social e a sua elucidação e exposição pelo pesquisador. Tal paradigma possui profundas raízes históricas, incluindo subjetividade, interesses, emoções e valores pessoais. Normalmente, em função desse paradigma, dados verbais são coletados, transcritos e analisados. Ou seja, depois de coletadas, são feitas transcrições das conversações dos participantes da pesquisa e seus relatos pessoais são organizados em função da distinção de sutilezas significativas de cada resposta dada pelo sujeito da pesquisa durante a realização da entrevista ${ }^{(13)}$.

Focalizando a subjetividade nas respostas da entrevistada, o método de pesquisa utilizado foi o qualitativo, com entrevista semi-estruturada por ser o mais apropriado para contemplar os aspectos subjetivos do envelhecimento. A entrevistada assinou um Termo de Consentimento Livre e Esclarecido, autorizando a realização da pesquisa. Foram garantidos os direitos de confidencialidade de sua identidade e voluntariado. Este projeto de pesquisa foi submetido e aprovado pelo Comitê de Ética e Pesquisa da Universidade Tuiuti do Paraná, sob o número 000102 2008, respeitando os aspectos éticos de pesquisas com seres humanos, conforme Resolução 196/96 do CNEP.

A entrevistada nasceu na cidade de Ponta Grossa, localizada no interior do Estado do Paraná. Ela tem 85 anos de idade, é viúva, pensionista e vive com uma filha solteira e um filho divorciado. Ambos os filhos têm mais de 40 anos de idade. Ela comenta que frequentou a escola por apenas três anos. Por isso, acredita não ter conhecimento formal suficiente para ser digna de escrever e publicar histórias, mas confessa que gostaria de escrever como uma grande escritora.

Frequenta o grupo da Oficina de linguagem há mais de cinco anos e, quando questionada sobre os motivos que a levaram a frequentar tal grupo, afirma que: " a principio por querer saber cada vez mais, ter um ambiente que me engrandece, me alegra, fico satisfeita em todos os sentidos, mas o principal é o que se aprende". Ela relata, também, se interessar pelas atividades escritas desenvolvidas na Oficina de Linguagem.

Sobre sua participação no grupo, ela diz que adora participar do grupo e contaria muito mais sobre suas histórias "se tivesse mais conhecimento, e se tivesse tido mais cultura para expor momentos da vida, por que às vezes tem momentos que a gente quer escrever e não encontra a palavra certa $e$ não encontra uma forma de se expressar, mas eu fico feliz de escrever do modo simples que estou escrevendo".

Quanto ao que a motiva a relatar parte da sua história de vida para grupo, ela diz: "acho que é a liberdade que a gente encontrou nesse grupo, a acolhida, nos incentiva e vai indo, vai indo que quando você toma conhecimento, você já expôs coisas da tua vida que às vezes você não conta para a melhor amiga. E aqui você encontra um ambiente onde você abre seu coração, e aí, então, nossas lembranças passam para os livros. E assim outras pessoas vão conhecer um pedaço das nossas histórias, mesmo que de um modo simples, mas que para bom entendedor poucas palavras bastam. A gente coloca nesse livro o que a gente pensa, o que a gente sente, o que a gente passou ou, até mesmo, o que a gente pretende, porque a vida está continuando".

A entrevistada afirma que a vivência no grupo da Oficina de Linguagem tem produzido mudanças na sua relação com a escrita porque "a cada dia que a gente participa, a gente tem novas idéias e ouvindo a conversa das companheiras, a gente vai lembrando de momentos e fazendo comparações e fica no anseio de passar para o papel aquilo que a gente lembrou, ou até comparações que a gente faz com os próprios companheiros do grupo".

Para a entrevistada, o grupo influencia na escrita da produção de sua história de vida para a organização de livros "por causa do incentivo, por que a gente a grosso modo em casa não teria, em casa escreveria como um diário, e aqui na oficina a gente encontra liberdade para escrever um livro que vai passando de mão em mão e que muitas pessoas lêem (...) a satisfação que nos trazem, isso é o que importa".

Disse também que, para ela, fazer parte de um grupo que tem por objetivo trabalhar a leitura e escrita de textos, significa "satisfazer pelo menos um pouco daquele medo tão grande que tive de ter estudado, e de até ser uma escritora, já me passou isso pela cabeça várias vezes, o sonho de ser uma escritora, (...), aqui escrevemos alguma coisa sobre a nossa vida, mas o nosso coração fica muito cheio de alegria e satisfação $e$ gratidão por essa paciência que vocês têm com a gente".

A entrevistada ainda faz a seguinte afirmação quanto ao o que significa para ela fazer parte de um grupo que tem por objetivos escrever livros: "é uma satisfação muito grande, é uma oportunidade que a gente não encontraria fora daqui".

Quanto ao seu envolvimento no grupo, a entrevistada faz a seguinte referência "é uma união, é uma família, a gente fica pensando, aguardando o dia de novamente vir aqui para conversar, para expor o nosso pensamento, eu que gosto de contar para as pessoas, de dar a opinião, mas a gente quer falar, quer dizer, quer ouvir, e a gente aprende muito”.

Quando indagada sobre o que significa para ela fazer parte de um grupo que conversa sobre suas histórias de vida a partir de textos diversos, a entrevistada responde: "eu acho que nós estamos em um caminho em que isso não devia ser só nesse grupo, nós como seres humanos devíamos ter todos essa oportunidade de conversar, abrir o coração, ouvir o que o outro tem a dizer, aí o mundo ainda chegará a um bom final se a humanidade for caminhando nesse passo como nós caminhamos aqui, que uma fala, a outra ouve, a outra opina, mas estamos todos coesos, pois o nosso objetivo é um só".

\section{DISCUSSÃO}

Os relatos que o sujeito de nossa pesquisa (a participante mais antiga do grupo da Oficina da Linguagem) elabora a 
partir de nossa entrevista, nos permitem perceber o quanto ela se sente bem por integrar esse grupo. Ela comenta que a Oficina é formada por um grupo que a possibilita saber cada vez mais, sendo um ambiente que a engrandece, alegra, satisfaz as pessoas em todos os sentidos. Mas o principal, ela diz, "é o que se aprende, conversando com o grupo, lendo para eles e escrevendo para eles e para quem quiser ler sobre as minhas histórias".

Ela declara, ainda, que no grupo, encontra espaço para falar, ler e escrever livre de correções da coordenadora da Oficina e dos demais integrantes. Relatou que após participar da Oficina, volta para sua casa pensando o que vai escrever para o livro e que à medida que vai lembrando de situações vai escrevendo.

Com essa passagem, é possível afirmar que sua participação no grupo lhe traz possibilidades de estabelecer um novo vínculo com a escrita, a partir da influência positiva que tal participação gera em sua produção textual. O grupo, dessa forma, apresentase como uma possibilidade de atender às necessidades dessa idosa. Ela percebe que, apesar do medo de escrever ocasionado pelo fato de ter frequentado a escola por um curto período de tempo, há o desejo de superação, com o apoio, confiança e expectativas do auxílio oriundo das relações constituídas no grupo. Convém ressaltar que a sua demanda associa-se não apenas a sua relação com a escrita, mas com a vida ${ }^{(14)}$.

No grupo há a possibilidade de cada um de seus participantes manifestar dificuldades e medos com relação ao uso da linguagem. Junto com tal manifestação são trazidas as demandas que fazem emergir sentimentos em comum acerca das relações com a linguagem, com a vida e com o próprio envelhecimento. Nos encontros grupais, é possível acompanhar a manifestação de sentimentos e exposição dos fantasmas relacionados à fala, a leitura e a escrita, favorecendo o processo de identidade grupal, tornando o grupo continente das angústias e necessidades de seus membros ${ }^{(14,15)}$.

De fato, é isso que podemos acompanhar em nosso estudo, principalmente, quando a entrevistada nos relata que a cada dia que participa do grupo, tem novas idéias e recordações de momentos da vida e fica no anseio de passar para o papel aquilo que se lembra, anunciando que a escrita deixa de ter uma conotação negativa relacionada ao seu medo de errar, ao tempo restrito que nossa idosa pôde frequentar a escola. Em direção contrária, a atividade escrita, vinculada com os conteúdos vivenciais de nossa idosa e de todo os membros do grupo, passa a ser encarada como uma aliada de suas lembranças e como passaporte para participar da Oficina de Linguagem. A escrita mediada no e pelo grupo dessa Oficina, tomada como atividade significativa ${ }^{(2,5)}$, passa a assumir um papel de destaque como parceira capaz de levar o grupo a atingir seu objetivo: a produção e organização de um livro que conta as histórias e os projetos da vida de cada participante. Assim, sem preocupar-se com medo de escrever "errado", nossa idosa mostra-se motivada a escrever cada vez mais.

Diante da coletividade, foi possível "ressignificar" suas dificuldades individuais. Em função dos processos interlocutivos desenvolvidos entre os sujeitos que compõem o grupo, sentimentos de medo e anseios em relação à linguagem, à vida e ao próprio envelhecimento foram compartilhados. Assim, percebendo que as dificuldades que assumia como suas, além de acolhidas pelo grupo, eram também comuns aos demais participantes, nossa idosa acabou por "ressignificá-las" na medida em que minimizou seus efeitos ${ }^{(5)}$.

A demanda de nossa idosa em torno das dificuldades enfrentadas, as quais a levam a perceber-se como excluída de uma sociedade que privilegia o novo em detrimento do velho, no grupo, garantem sua participação como contadora e escritora de suas histórias de vida. Para ressaltar nossa afirmação, convém explicitar a resposta que nossa entrevistada dá, quando questionada sobre a importância dos componentes do grupo no processo da escrita da sua história: "O mais importante para mim é a dedicação de vocês, o lugar que vocês nos dão. Eu gosto muito de vocês porque vocês têm uma maneira de entender a gente, uma maneira de lidar com as pessoas que não é qualquer pessoa que se propõe, (...), Vocês entendem o nosso não saber, a nossa parte. Me sinto importante com a dedicação e o empenho de vocês. Sem esse empenho, este livro não seria feito". Em uma situação em que o grupo estava reunido, conversando sobre o significado que o envelhecimento assume para cada um, nossa idosa disse: "eu espero que quando vocês ficarem velhos encontrem pessoas que, como vocês, tenham paciência com os idosos, porque isso não é muito fácil de se achar hoje em dia...pessoas que valorizem os mais velhos".

As mediações da coordenadora da Oficina, dos estudantes de Fonoaudiologia e Psicologia, bem como dos mestrandos e doutorandos em Distúrbios da Comunicação no sentido de promover situações interlocutivas nas quais os idosos puderam explicitar seus sentimentos de menos valia e de limitações para fazer uso da linguagem foram determinantes para provocar revisões em torno do envelhecimento e da possibilidade de escrever nesse momento de vida. Essas mediações, em função de constantes questionamentos, desestabilizam posições assumidas pelos idosos como desvalorizados, improdutivos, privados de saber, incapazes para escrever ${ }^{(12,14)}$. Na atuação grupal, calcada em uma perspectiva que toma a linguagem como atividade que constitui permanentemente subjetividades a partir de trabalhos intersubjetivos, posições pessoais podem ser reavaliadas $^{(10)}$. E isso parece ficar claro quando nossa idosa afirma sentir-se importante a partir da dedicação do outro. É exatamente esse empoderamento, esse sentimento de aumento de poder pessoal que viabiliza a escrita de um livro de histórias.

Em uma passagem do relato da entrevistada, ela comenta que, no grupo, expõe coisas da sua vida que às vezes não contaria nem mesmo para sua melhor amiga, pois, na Oficina, encontra um ambiente em que sente tranquilidade para falar com liberdade, sem medo de ser julgada. Ela comenta também que escrever "é a oportunidade que tem para transferir em palavras escritas, momentos de emoções que estão enjaulados, feras feridas, que encontram a liberdade no momento em que seus textos podem ser lidos no grupo". Com esse comentário, podemos perceber claramente que o grupo tem papel fundamental no desenvolvimento de atividades escritas e de como elas são intensas para nossa idosa ${ }^{(10,14)}$.

A entrevistada nos pontua que, por causa do incentivo que o grupo oferece, encontra liberdade para escrever um livro que vai passando de mão em mão e que muitas pessoas lêem. Ela ainda observa que este incentivo é algo que não encontraria na sua própria casa, por exemplo, e que agora consegue imaginar 
seu livro na prateleira para que seus netos e bisnetos possam o ler, e que isso lhe traz ainda maior prazer e motivação.

Para finalizar essa discussão é importante destacar que antes de sua inserção no grupo, a entrevistada encontrava-se imersa no discurso social vigente de uma sociedade calcada nos preceitos de produtividade e eficiência, que afirma que quem não estuda não pode participar de modalidades de gozo social $^{(10)}$. Mas, conforme acompanhamos nessa pesquisa, o grupo pode desestabilizar preconceitos e ditos, à medida que promove possibilidades para mudar essa visão de estagnação e menos valia de velhos que tiveram um acesso restrito ao ensino formal. A partir dessas possibilidades, nossa idosa passa a ter expectativas positivas em relação às suas produções escritas e, também, ao olhar do outro, e dela mesma em relação a si própria. Dessa forma, o grupo apresentou-se como uma possibilidade de atender necessidades subjetivas de nossa idosa, proporcionou-lhe mudanças nas relações com a linguagem, na medida em que ela depositou no grupo confiança e expectativas de que as relações interpessoais que estabeleceu fossem capazes de influenciar favoravelmente os sentidos que ela mesma atribuiu à sua fala, à sua escrita e ao seu próprio processo de envelhecimento $^{(10,14)}$.

\section{COMENTÁRIOS FINAIS}

Com esse estudo é possível confirmar, que um trabalho grupal pode desempenhar um importante papel na reelaboração de vínculos entre idosos e atividades com a linguagem escrita. A configuração do grupo da Oficina de Linguagem com sua estrutura e características específicas, uniu sujeitos, nesse caso pessoas com mais de sessenta anos, possibilitando que esses sujeitos assumissem posição de interlocutores uns dos outros.

Essa interação tem convocado a reorganização da história de vida de cada integrante da Oficina, pela via da oralidade e, sobretudo, da escrita. O grupo, dessa forma, viabilizou situações que permitiram que o sujeito da pesquisa flexibilizasse posicionamentos e abrissem novas possibilidades de se relacionar com ela própria e com a linguagem escrita.

A constituição de um grupo, portanto, possibilita que os sujeitos que o integram passem a agir com e sobre a linguagem de maneira capaz de gerar mudanças e transformações nas relações que estabelecem com a leitura e a escrita, a partir da organização de relatos de suas histórias no e para o grupo.

\section{AGRADECIMENTOS}

Agradecemos ao Conselho Nacional de Desenvolvimento Científico e Tecnológico(CNPq), pelo apoio concedido para realização dessa pesquisa, sob processo número 307272/2008.

Agradecemos a "Y", idosa participante dessa pesquisa, pela generosidade, acolhimento e respeito pelo nosso trabalho.

\begin{abstract}
The aim of this study was to analyze the role of an elderly group in the development of writing activities directed to one of the participants of this group, which was consolidated after a Language Workshop. This case report was based on an interpretative paradigm, which includes subjectivity, interests, emotions, and personal values. Transcription analyses of the semi-structured interview conducted with a n 85-year-old member of a Language Workshop from Curitiba (PR, Brazil), were performed. To the interviewee, the Workshop is an empowering environment, that makes her feel encouraged and welcome in the group, and that allow her to expose life facts through writing. It was her participation in the group that, according to her own report, awakened the desire and courage to remember, rearrange and translate her stories into words, so that others could read them. The close relationship between the bond between the interviewee and the group and her possibilities of written production is evident. Participating in the group has been generating changes and transformations in her way to relate to her written productions elaborated during the organization of reports of her life stories in the group and to the group.
\end{abstract}

Keywords: Aging; Handwriting; Group structure; Interpersonal relations; Language arts

\title{
REFERÊNCIAS
}

1. Freitas E. Demografia e epidemiologia do envelhecimento. In: Py L, Pacheco JL, Sa JL. Tempo de envelhecer: percursos e dimensões psicossociais. Rio de janeiro: NAU; 2004. p. 19-38.

2. Gamburgo LJ, Monteiro MI. Singularidades do envelhecimento: reflexões com base em conversas com um idoso institucionalizado. Interface (Botucatu). 2009;13(28):31-41.

3. Jardim SE. Aspectos socioeconômicos do envelhecimento. In: Papaléo Netto, M. Tratado de gerontologia. 2a ed. São Paulo: Atheneu; 2007. p.185-98.

4. Hammerschmidt KS, Zagonel IP, Lenardt MH. A critical analysis of gerontological nursing practice guided by Leininger's theory of culture care diversity and universaity. Acta Paul Enferm. 2007;20(3):362-7.
5. Massi GA, Torquato R, Guarinello AC, Berberian AP, Santana AP, Celebrone LR. Práticas de letramento no processo de envelhecimento. Rev Bras Geriatr Gerontol [Internet]. 2010 [cited 2011 Fev 16];13(1). Available from: http://revista.unati.uerj.br/scielo.php?script=sci_ arttext\&pid=S1809-98232010000100007\&lng=pt.

6. Massi GA. A outra face da dislexia. [tese]. Curitiba: Universidade Tuiuti do Paraná; 2004.

7. Machado ML, Berberian AP, Massi GA. A terapêutica grupal na clínica fonoaudiológica voltada a linguagem escrita In: Santana AP, Berberian AP, Guarinello AC, Massi GA. Abordagens grupais em fonoaudiologia: contextos e aplicações. São Paulo: Plexus; 2007. p.58-79. 
8. Laplane AL, Batista CE, Botega MB. Grupo de avaliação e prevenção de alterações de linguagem. In: Santana AP, Berberian AP, Guarinello AC, Massi GA. Abordagens grupais em fonoaudiologia: contextos e aplicações. São Paulo: Plexus, 2007. p.164-87.

9. Souza AP, Crestani AH, Vieira CR, Machado FC, Pereira LL. O grupo na fonoaudiologia: origens clínicas e na saúde coletiva. Rev CEFAC. 2010;13(1):140-51.

10. Lourenço RC, Massi A. Linguagem e velhice: considerações acerca do papel da escrita no processo de envelhecimento. Curitiba: Juruá; 2011.

11. Bosi E. Memória e sociedade: lembranças de velhos. 6a ed. São Paulo: Companhia das Letras; 1998.
12. Novaes B, Rudge AM. A função da linguagem em Bakhtin e Lacan. Tempo Psicanál. 2007;39(1):157-78.

13. Moreira H, Caleffe LG. Metodologia da pesquisa para o professor pesquisador. Rio de Janeiro: DP\&A; 2006.

14. Machado ML, Berberian AP, Santana AP. Linguagem escrita e subjetividade: implicações do trabalho grupal. Rev CEFAC. 2009;11(4):713-9.

15. Wiethan FM, Souza AP, Klinger EF. Abordagem terapêutica grupal com mães de crianças portadoras de distúrbios de linguagem. Rev Soc Bras Fonoaudiol. 2010;15(3):442-51. 